\title{
IMPLEMENTATION DRIVERS FOR BPR AT SIEMENS TELECOMMUNICATIONS
}

\author{
CC Koorts \\ Department of Industrial and Systems Engineering \\ University of Pretoria \\ South Africa \\ PJ Conradie \\ Department of Industrial and Systems Engineering \\ University of Pretoria \\ South Africa
}

\begin{abstract}
With the embracing of new management philosophies or redesigned processes, it is becoming a popular opinion that often the practical problem lies with the implementation of the new concept, rather than with the concept itself. By focussing on certain generic critical actions, chances of successful implementation increases for any new philosophy or re-engineered process. This article discusses such critical success actions, or implementation drivers as experience in a BPR project at Siemens Telecommunications.
\end{abstract}

\section{Opsomming}

' $n$ Gewilde siening ten opsigte van die bekendstelling van nuwe bestuursfilosofiee,, of implementering van herontwerpde prosesse, is dat die probleem gewoonlik lê by die implementering daarvan, eerder as by die beginsels van die bestuursfilosofie wat geimplementeer word. Deur op generies kritieke faktore te konsentreer, kan die kanse op suksesvolle implementering van bykans enige bestuursfilosofie of herontwerpde proses verbeter word. Hierdie artikel bespreek sulke kritieke sukses aksies, of implementeringsdrywers, aan die hand van 'n gevallestudie soos ervaar in ' $n$ BPR projek by Siemens Telecommunications. 


\section{Introduction}

Almost any fair sized organisation in this age of management philosophies knows shopping lists of three letter acronym buzzwords. Organisations also know the euphoria and delusions connected to them, having their own reservations about whether they work or not. Theoretically any management philosophy makes sense the trick is to get it working in practice. The balanced scorecard as example was crowned as the management philosophy of the late nineties, but also received its fair share of criticism. In its defence its propagators stated that "if the balanced scorecard has received any criticism, it is related to the effort involved in its implementation" [1]. Similarly, advocates of other management philosophies tend to agree that the problem more often lies with implementation. Faull, Day and Klein presented a paper [2] in which they stated that no matter what philosophy being implemented (TQM, BPR, Lean Production), success depends on the use and presence of certain critical success factors during implementation.

As is the case with most new philosophies, the guru author provides a list of 'Do and Don't' rules related to the implementation of the philosophy, assuring that if implementers abide by these rules, they should be successful. But as Hammer stated "people are remarkably resourceful in finding ways to drop the ball" [3] and abiding by the 'Do and Don't' rules will not necessarily guarantee success. Instead management must face the fact that they will make mistakes during implementation of management philosophies, but as long as they counter their mistakes by investing enough energy in critical success actions, implementation will be positive in its effects on the organisation. It should be added that successful implementation varies in perspective. Some managers would like to see quantified Economic Value Added (EVA) benefits, while others are satisfied by a mere culture chance. For the sake of this article successful implementation is seen as the implementation of a reengineered process as designed.

This article is based on a case study that looks at five specific critical success actions, or implementation drivers that the Siemens Telecommunications organisation encountered during its efforts to implement Business Process Re-engineering (BPR) solutions. Siemens Telecommunications is a major supplier of telecommunication equipment and was forced to undertake a BPR exercise due to the change in the South African telecommunication market. [4] These implementation drivers were compared with 'Do and Don't' rules from various literature studies, and seem to emerged as recurring rudiments for the implementation of any new management philosophy, newly designed process, or even new techniques to be implemented on production lines. The five implementation drivers are:

1. Assigning appropriate ownership to re-engineered processes,

2. Campaigning the objectives and later the results from re-engineering,

3. Planning and resourcing the implementation phase properly and manage it as a business project,

4. Measuring Key Performance (KPI's) Indicators regularly and make the result visible, and

5. Utilising Information Technology tools as enablers for the new processes. 
Each one will be discussed with references to literature studies, other case studies and practical experience.

\section{Implementation Drivers}

Being a filial of a global German company, Siemens Telecommunications was familiar with implementing improvement initiatives, or rather, the attempts to implement initiatives. Most of the time initiatives were forced upon the organisation as management philosophies in the form of "mother company policies". These policies also had their logic based on popular buzzwords (MRP, SOP, TQM), some even on German variation acronyms (öv, äct, top), but how to make them work in practice always got lost in the translation of the 'Do this' rules. The effect was that when Siemens Telecommunication's management was forced to re-engineer the organisation in order to adapt in its changing market, the scars of policy implementation caused hindrance. The organisation did not believe improvement initiatives were needed, or would work, and management force would not suffice. Certain organisational levers had to be applied.

In what is probably the most well known transformation case study, [5] Jack Welch describes how he had to seize the "revolutionary's three main levers of control, namely the police, the media, and the schools" to communicate his vision and implement his values for GE.

\subsection{Assign appropriate ownership to re-engineered processes}

The need for top management commitment goes without saying. Nearly every management philosophy guru stresses the importance of high profile commitment. Appropriate ownership requires this commitment as a prerequisite, but goes beyond that by addressing Jack Welch's primary concern of "how to make the leaders walk the talk". [5]

As one of his ten commandments for implementing the balanced scorecard, Claude Lewy encourages that " a top-level (non-financial) sponsor backs the initiative and that relevant line managers are committed to the project. The balanced scorecard project is too big to be anything other than top priority, and it should never be left to the accountants to do". [6] Because the balanced scorecard is a management system, executive management has to take ownership of it and cannot leave it to a task team.

Robert Kaplan interviewed Larry D. Brady from FMS Corporation regarding their success with the balanced scorecard implementation. [7] His comment was that FMC also tried to implement many of the popular improvement programs, but had not been effective. Each time their people would ask: "How is that supposed to fit in with the six other things we're supposed to be doing?" The problem seemed to be the diversity of initiatives, each with its own slogan being pushed by corporate staff groups. To implement the balanced scorecard FMC's executive management had to commit their division managers to develop their own prototype scorecards for their operations. Larry Brady replies "that was an essential part of creating consensus between senior and divisional management on operating objectives".

When it comes to making re-engineering work, Hammer states that "seniority and authority is not enough". [3] He urges that whoever leads the project needs to 
understand the mindset of the processes, as well as the link between operations and finance. Siemens Telecommunications addressed this concern by assigning appropriate owners for new processes, and making them manage their new processes. Ownership has to be assigned at three levels:

1. Top management - For implementation to be successful, top management needs to ensure they have structured their organisation and aligned the strategy to accommodate the new processes. Imperatively a senior manager has to accept ownership as coach of the new process and resources that were assigned to implement and operate the new process.

2. Middle management - The manager that will be responsible for the new process in the future, must take over the ownership of the new process even before it gets implemented. No external consultant can implement a process for a manager. This new process owner must work with his process team to implement the changes to the process, and as a group they must give feedback to their process coach.

3. Operational level - The future operators of the process must also be the process team to implement the new process. This process team must understand the significance of the process in the organisation's operations and accept ownership in supplying quality products or services.

To ensure proper BPR implementation, the director who acted as coach for the logistics processes, relieved all his managers from their day to day activities and charged them with the task of implementing the new procurement, shipping and warehousing processes. For this reason the implementation of the logistics processes were considered to be most successful with Siemens Telecommunication. [4] Jack Welch affirms this behaviour in his comment: "Managers had to know how to initiate change, how to accelerate it, and how to make it stick - people who are comfortable as coaches and facilitators will be the norm at GE. And the other people won't get promoted." [5]

\subsection{Campaigning objectives and results of re-engineering}

IBM is another example of a company that gone through a period of losing every possible market position during the late 80 's, thanks to executives who were too busy fighting turf battles. But somehow IBM got itself refocused during the mid 90's to catch the Internet wave and become positioned to once again lead from the front. [8] Inside IBM and out, David Grossman and John Patrick are today recognised for their pivotal contribution to their company's e-business metamorphosis. With the support of a pro-change CEO, these two unlikely heroes - a software nerd and a corporate staffer - helped waking up IBM. None of them had authoritative positions to drive the metamorphosis in IBM, but through various means of communication they preached about how IBM could leverage the Web. They started their campaign in 1994 with Grossman building a primitive corporate Intranet, and Patrick published a nine-page manifesto entitled "Get Connected". It was distributed informally by email, and found a ready audience among IBM's unheralded Internet aficionados. From there on they took every opportunity to deliver their e-business message, they would set-up on-line news groups, demo a mock-up of an IBM homepage to top officers, partake in Internet World trade conventions, an do anything to keep the grassroots communication going. Patrick was a relentless campaigner, spreading the 
good word of the Internet in countless speeches inside and outside IBM. Even when talking to reporters, his prime constituency was still the vast swath of unconverted IBM'ers. And then the penny dropped: in 1996 for the first time the Olympics would have an official web site, and IBM would build it.

Such communication in various forms is also important when implementing new management philosophies or re-engineered processes. Professor Claude Lewy urges balanced scorecard implementers "not to underestimate the need for training and communication. Even if the idea seems simple, the huge change it causes has to be dealt with". [6] For BPR, firstly the objectives, and then later on early successes, need to be communicated to the organisation to promote buy-in for implementation. These types of campaigning actions are related to what Professor Norman Faull referred to as Adoption management. [2] It includes marketing of the BPR project internally, ensuring user participation, providing training and giving effective feedback.

A comment from one of Siemens Telecommunications' directors was "The problem with communication is that we always seem to have problems with it, no matter what we do". For the BPR project a special 'Communications and Mobilisation' team was formed to look after communication. Campaigns to communicate BPR objectives started off by means of:

- Roadshows and Brown Paper Fairs about BPR objectives, how new processes look and what is implementation progress.

- Publications about the BPR project in newsletters, e-mails and on the Intranet.

- Competitions and awards for participation in initiatives and even just lucky draws for attending Brown Paper Fairs.

But to make organisation buy-in successful, campaigning had to be taken even further to achieve involvement. This was achieved through:

- Onboard training of all employees that need to participate during reengineering and later on training process teams on the designs of new processes.

- Getting operators and staff to validate processes on Brown Paper Fairs.

- Inviting employees to participate in workshops and be part of teams.

The roadshow was a touring presentation given at different divisions with the purpose of delivering a mobilising message about why Siemens Telecommunications had to re-engineer. It was accompanied by visual displays of financial results and market trends, but reassurances were also given regarding job securities. Then as BPR got underway, Brown Papers were used due to its ability to prompt participation. A Brown Paper is a visual snapshot of an entire operating process highlighting all applicable interfaces, documentation, and data sources, and is called a Brown Paper because it is constructed on brown paper. [9] A Brown Paper Fair is a special exhibition where the organisation is invited to have a look at such Brown Papers presenting the BPR initiatives and processes. 


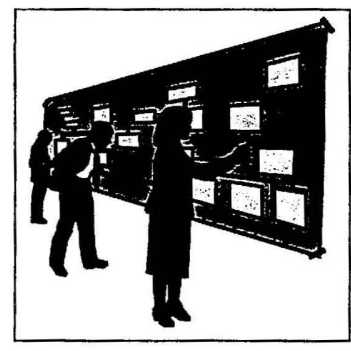

Figure 1. Campaigning with Brown Paper Fairs

Brown Paper Fairs were experienced to be the most effective campaigning tool during Siemens Telecommunications' BPR project. Because of its 'low-tech, hightouch' characteristic everybody could easily relate to this form of communication and easily participate ideas onto a Brown Paper. Even after the BPR project were implemented and finished, process teams looking at new areas of improvement still requested that Brown Papers should be build to communicate ideas to the rest of the organisation.

This example stresses the fact that communication in its simplest and most consistent form is the most effective. Jack Welch explains how communication evolved in GE: "We have learned a bit about what communication is not. It is not a speech like this, or videotape. It is not a plant newspaper. Real communication is an attitude, an environment. It's the most interactive of all processes. It requires countless hours of eyeball-to-eyeball back and forth. It involves more listening than talking. It is a constant, interactive process aimed at consensus". [5] Even though Siemens Telecommunication's management felt that there would always be communication issues, it was not a matter of giving up. By constantly campaigning messages, an environment is created in which the organisation can see and understand its changes.

Campaigning is not only important during the course of implementing a new process or management philosophy, but is also important to continue after implementation. If an organisation is given feedback of the success accomplished due to implementing a new strategy, it will be more willing to trust management the next time an improvement initiative is undertaken.

\subsection{Planning and Resourcing the implementation phase}

One of the more difficult steps during BPR is moving from design phase into implementation phase. Process teams will have a lot of wonderful To-Be designs on one hand, and related As-Is processes on the other, and the question is how to manage transition from 'As-Is' to 'To-Be'.

When implementing a new process, the challenge is how to start off with the one right initiative that will cause successful implementation of the whole new process. As one solution to this dilemma, experts with a strong theoretical background and a good understanding of practical operation, can be used to plan implementation. These experts must have the ability to bring theory to practice, conceptualise the new process' working, and plan a road for implementation. As another solution, the best practice that will be evident in the new process must be focussed on, with the attention on activities to put the best practices into place. Where the desired best 
practice is a result of a re-engineered process, aim implementation planning at putting enablers in place to achieve that best practice. Take for example the objective to implement Customer Relationship Management (CRM). This philosophy calls for understanding customer needs and using that knowledge to provide a 'total solutions package' that will provide value for all involved parties. An approach to implement CRM is to start with a Quality Function Deployment (QFD) exercise on a product or service to gain knowledge of specific customer requirements. Identify the product and service characteristics which are important to provide optimum customer value. Value Engineering can then be applied to ensure product and service specifications fulfil in all the requirements for customer value. Once the organisation is sure it can satisfy its customer's 'total solution needs', a Service Level Agreement (SLA) can be negotiated that benefits both parties. If all these activities have been accomplished, a base is formed for maintaining CRM.

During implementation the effectiveness of running a pilot should never be underestimated. Unfortunately the time planned for running pilots are often underestimated. Pilots provide valuable lessons without over exposing the organisation to risk. With the running of an R3 Project Schedule pilot within Siemens Telecommunications it was found that the success from it, was a campaign in itself for organisational wide implementation.

Another dilemma during the implementation is the availability of resources. Hammer warns not to "skimp on the resources devoted to reengineering". [3] BPR is an effort that needs time and attention from the organisation's best people in addition to direct senior management involvement. Skimpy resources send out signals of nonimportance. Usually during the BPR implementation phase, the fun work of redesigning processes are done, more often than not the consultants flee the scene, and nobody feels like confronting the resistance-to-change to implement the new processes. Top management must be aware that it takes more energy to implement processes than to design them and even though the implementation job is duller and slower than the creative design phase, it is more complex due to confronting organisational resistance and solving teething problems.

This was exactly what was experienced with the implementation of Siemens Telecommunications' BPR project. Thirteen full-time staff were involved during the BPR design phases, but at the beginning of the implementation ten of the 13 staff rather took up other positions in the organisation. Management then realised the need for more resources and the implementation team was increased to 18 full time resources. The ideal resources at this stage should be the future process owners with members from the design teams acting as consultants to implementation. From the IBM example, John Patrick's solution to his resource problems was to borrow people from various business units. [8] $\mathrm{He}$ would assure the donor-managers that the relationship he was forging works both ways. He'll have a temporary resource for his virtual team, and the manager will get an engineer back with Internet references and experience.

Effective planning and resourcing, as part of the Project Management function of implementation, will automatically lead to better monitoring and control of the implementation project, which in itself is vital to successfully control the changes brought about by re-engineering. Kachellek emphasised the importance to "Control the changes (do not go too fast nor too slow)". [10] In addition to these Project Management functions, the importance of finalising the documentation must be 
stressed. By capturing the re-engineered processes, or implemented philosophies in formalised ISO 9000 procedures, process sustainability can be supported.

\subsection{Visible measuring of Key Performance Indicators}

When implementing a philosophy that expects an organisation to change its strategy, Larry Brady from FMC suggests "you had better change the system of measurement to be consistent with the strategy". [7] From their experience, "the FMC executive team had to be able to assess, through measurement of their operations, whether or not the divisions were meeting their strategic objectives". Similarly for re-engineering processes, Key Performance Indicators (KPI's) should be designed into the processes as part of its improvement. Once operators realise that KPI's provide transparency to processes for perceiving improvement and providing top managers with better insight into operations, they will make an effort to produce positive KPI's. If a process was well designed, KPI improvement and process improvement are directly related.

In Siemens Telecommunications KPI's form the basis of benefits cases and balanced scorecard results:

- Benefits cases indicate the Economic Value Added (EVA) by the BPR project, thus the executive management wants monthly updates on these figures. Process owners know that the KPI's they have to provide are directly related to EVA benefits. Thus the better their KPI's, the better they look towards management in financial terms, which in turn is a reflection on their processes. One of the EVA benefit examples is the objective to consolidate all transportation activities to reduce freight costs. As KPI's the percentage of transportation organised through the shipping department, and the consequent freight cost per kilogram are measured. Over the last two years improvements in these KPI's related to an EVA benefit in excess of R2 million per annum. [4]

- Siemens Telecommunications' balanced scorecard is based on an executive dashboard that segregates into various departmental dashboards with each having their own KPI's. Management requires regular feedback on dashboards with measurements varying from monthly to annually, and if process owners have problems reaching targets, reasons have to be provided. In this manner attention can be given to processes that are still not properly implemented. An example of dashboard KPI's which were linked to process improvements are the measurement of Installation and Commissioning overtime. As one of the internal process KPI's, the amount of Installation and Commissioning overtime are measured as a percentage of normal time. In order to reduce the overtime percentage, time wasted have to be reduced by means of better activity planning and improved interaction with logistics processes. Additional benefits are improved customer satisfaction due to projects completed on time, and less cost overruns because of overtime paid. Figure 2 also illustrates this interaction in the Installation and Commissioning's Dashboard. 


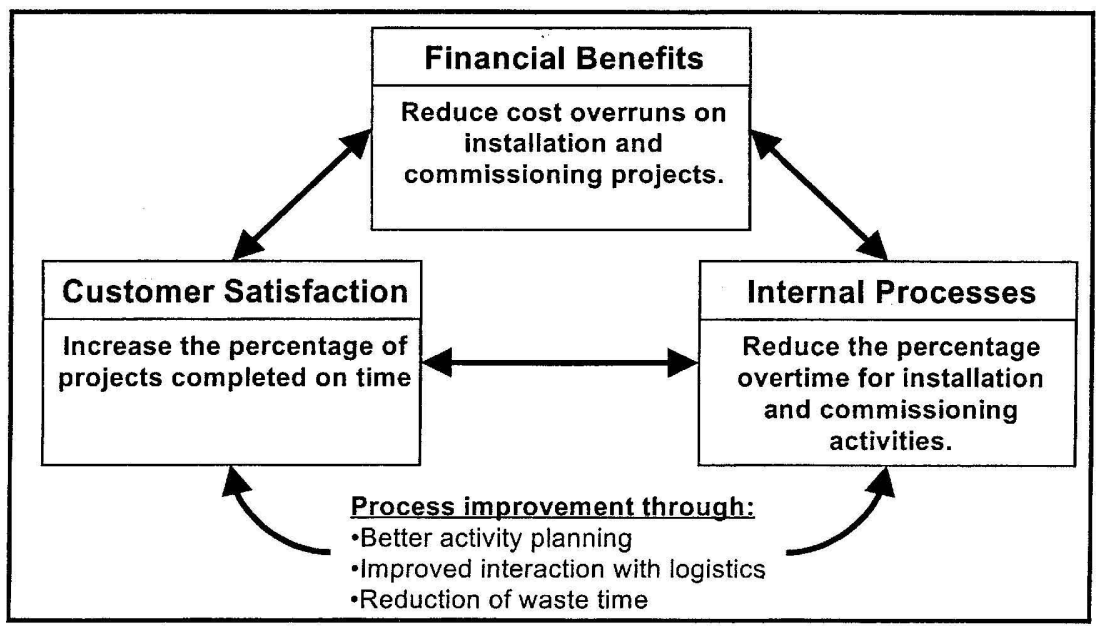

Figure 2. Process improvement measured through Dashboard KPI's.

Unfortunately data availability is a regular concern when it comes to KPI measuring, but as part of new processes or strategies, systems to provide relevant data must also receive attention during implementation. In the areas where management had interest in KPI's, the relevant process owners made an effort to implement initiatives in order to improve performance.

\subsection{Utilise Information Technology tools as enablers}

In his initial article about re-engineering, Hammer pleaded the case to "use the power of modern information technology to radically redesigned our business process in order to achieve dramatic improvements in their performance." [11] Now, a decade later, any type of BPR or change management exercise cannot be attempted without utilising the benefits of Information Technology (IT). Ironically, the opposite problem is being experienced. IT tools are often seen as miracle problem solvers that will provide all the process solutions, and the less known about the application, the better miracle it is. But when process owners realise what the systems actually do, more resistance against the new system and the management philosophy it supports, amounts in the form of complaints about additional work the system might cause.

IT systems such as Enterprise Resource Planning (ERP), Finite Capacity Scheduling, Supply Chain and Manufacturing Process Control, or Business Intelligence systems for balanced scorecard measuring, are not miracle workers. When implemented it relates more to Jack Welch's police like monitoring systems than the problem solving miracles. For a system to be used as proper support to a process or strategy, workflow management must effectively be designed into the equation. Workflow can be described as the flow of information and control in a business process. Consequently workflow management is the efficient management of this flow of information and control in a company's business processes. [12] Figure 3 indicates workflow triggering in a Goods Receive process where an ERP system is used to optimise decision making. Thus the ideal is to design processes 
with knowledge of the intended IT application to be used in mind, and indicate system interaction on process designs as workflow triggers that serve as instigators for activity continuation. These workflow triggers can be identified through workflow analysis that define information and control hand-over or interventions in the business process.

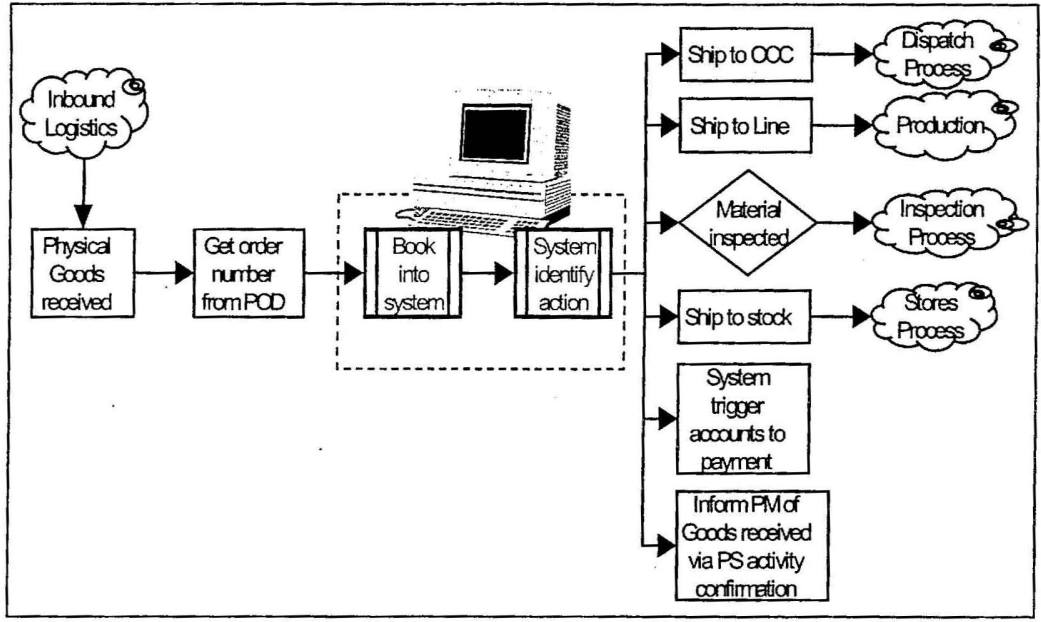

Figure 3. A Goods Receive process with designed in workflow triggers

Process implementation combined with application implementation can then be compared to moving down a one-way road. Once both are implemented there is no return to old ways of doing things - it is prevented by the system.

When procurement was centralised in Siemens Telecommunications, the ERP system provided leverage in terms of making people follow the centralised requisition release and procurement process. There were people who tried to misuse the system by trying to use it as a typewriter to printout purchase orders and procure outside the formal process. These individuals were oriented and trained in the process and proper use of the system, and when they continued to misuse the system, their authorisation were simply taken away and they were forced to make use of procurement experts.

Another example of IT enablers with similar implementation persuasion are Business Intelligence systems that provide the ability to report critical corporate data efficiently and in real time. Based on On-Line Analytical Processing (OLAP) and data warehousing, interactive reports provide selective chunks of information to decision-makers. [13] These status reports are especially effective for KPI reporting, business performance reporting and scorecard keeping.

\section{Conclusion}

Implementation of new processes and philosophies is never easy. It takes a lot of energy and time. The total BPR project at Siemens Telecommunications took 19 months, from the initial training of the first project team members until final hand- 
over to all the process owners. Nine months were spend on As-Is analysis, Should-Be modelling, design of aspirational models, and To-Be process design phases. Ten months were spent on implementation. During the total project a lot of time was spent on the following critical success factors (also referred to as Implementation Drivers):

1. Assign appropriate ownership to the re-engineered processes.

At top management level.

$>$ At middle management level.

$>$ At operator level.

2. Campaign the objectives and later the results from re-engineering.

$>$ Utilise various means of communication.

$>$ Request employees to validate processes.

$>$ Involve all relevant role-players in workshops.

$>$ Train process owners in the new processes and philosophies.

3. Plan and resource the implementation phase properly and manage it as a business project.

$>$ Plan implementation to start off with the one right action.

$>$ Use Best Practice causes to focus attention during implementation.

$>$ Run pilots to learn valuable lessons and reduce risks.

$>$ Ensure sufficient resource availability for implementation.

4. Measure Key Performance Indicators regularly and make the results visible.

$>$ Design process KPI's to reflect process improvement.

$>$ Use KPI's to measure EVA benefit of process improvement.

$>$ Link process KPI's to the Balanced Scorecard.

5. Utilise Information Technology tools as enablers for the new processes.

$>$ Know the IT application to be used and design its interaction as workflow triggers into the new process.

$>$ Concurrent process and IT application implementation take the organisation down a one-way path that prevents reverting back to old ways of doing things.

To drive his transformation of GE, Jack Welch used a concept that he called 'Work-Out'. [5] It was a combination of using his levers of the revolution, building trust, empowering employees, elimination of unnecessary work, and defining a new paradigm for GE. This article suggests that a 'Work Out' is indeed necessary to implement new management philosophies, or reengineered processes. However, instead of abiding to lists of "Do's and Don'ts", hoping for the new process or philosophy to work, sufficient skill and energy should be applied to implementation drivers to ensure a successful outcome. 


\section{References}

[1] CorVu Whitepapers: "Automating the Balanced Scorecard" http://w3.corvu.com/library/whitepapers.html; 1999

[2] Faull, Norman; Day, Nick; Klein, Tanja: "What does good implementation look like?"; SAPICS '98 Integrating the Supply Chain p.10-1 - 10-14.

[3] Hammer, M and Champy, J.: "Reengineering the corporation" 1993; p $200-$ 213

[4] Tirisano project team, Siemens Telecommunications: "Top+ Team Award: Cost Reduction" 1999

[5] Noel Tichy: "Control your destiny, or someone else will (How Jack Welch Transformed General Electric)"; 1993 - p. 54, 62-65, 76-79, 90, 196-209.

[6] McCunn, Paul: "The Balance Scorecard...the eleventh commandment" Management Accounting: Magazine for Chartered Management Accountants, December 1998, Volume 76; p34-36

[7] Kaplan, Robert S. and Norton, David P.: "Putting the Balanced Scorecard to work"- Harvard Business Review September-October 1993; p134-147

[8] Hamel, Gary: "Waking up IBM" - Harvard Business Review July-August 2000; p137 - 146

[9] Gemini Consulting: Jargon Dictionary (excerpts from) [Gemini Consulting Ltd 1998]

[10] Kachellek, Alexander: "Changing a culture from 'This will do' to 'This is the best way"'; SAPICS '98 Integrating the Supply Chain p.15-1 - 15-9.

[11] Hammer, Michael: "Reengineering work: Don't Automate, Obliterate" Harvard Business Review July - August 1990; p. 131 -139.

[12] Gfi Whitepaper: "Workflow Technology - an introduction" http://www.gficomms.com/index.html; 1999

[13] Cognos Whitepaper: "OLAP reporting for the Enterprise"http://www.cognos.com/olap/olapwp.html; 1999 